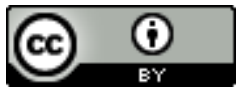

Esta obra está sob o direito de Licença Creative Commons Atribuição 4.0 Internacional.

\title{
INFECÇÃO CRUZADA NA ODONTOLOGIA: RISCOS E DIRETRIZES
}

\section{Dilson Cavalcante Tenório ${ }^{1}$}

José Silva de Menezes ${ }^{2}$

Betijane Soares de Barros ${ }^{3}$

\section{RESUMO}

O propósito desta revisão de literatura baseou em discutir sobre o desafio dos profissionais em odontologia diante a infecção cruzada na odontologia. O controle da de infecção na prática odontológica, pode ser realizada através da implantação de um protocolo, com inúmeras as medidas capazes de interferir na cadeia de infecção, proporcionando um atendimento odontológico seguro ao paciente. (KOHN,2004). A prevenção da infecção deve ser por meio de métodos educativos que ressaltam a necessidade da vacinação, é necessária para evitar um ciclo de transmissão, tendo em vista que a prevenção é o melhor caminho para resguardar o bem-estar dos pacientes e dos profissionais envolvidos em odontologia.

Palavras-chave: Controle de infecção; Odontologia; Educação em saúde.

\footnotetext{
${ }^{1}$ dilsontenorio4@hotmail.com

2 Jaelson_menezes@hotmail.com.

${ }^{3}$ bj.bs@hotmail.com
} 


\section{INTRODUÇÃO}

Segundo Barreto et al. (2011) os profissionais de saúde estão expostos a risco de infecção cruzada, ou seja, transmissão de agentes infecciosos dentro do ambiente clínico. O contágio se dá geralmente através do contato de pessoa para pessoa, pelo ar ou através de objetos contaminados.

Para Azeredo et al. (2011) o ambiente clinico necessita de procedimentos de proteção contra possíveis riscos infecciosos, através de esterilização e desinfecção, garantindo maior proteção aos pacientes e ao próprio profissional. Khan et al., (2012) relata que a incidência de contaminação cruzada está relacionada o fato de profissionais da área odontológica não adotarem métodos eficazes de controle de infecção em seus consultórios.

Fialho (2011) cita a importância da conscientização dos riscos de contaminação durante o atendimento odontológico, já que geralmente as infecções estão relacionadas aos instrumentos odontológicos, assim, durante a realização dos procedimentos odontológicos há uma exposição de todos os envolvidos na atividade. Apesar de expor pessoas às doenças infecciosas, grandes partes desses profissionais ainda se mostram resistentes à adoção de medidas de controle de infecção.

O mesmo autor relata que a segurança no ambiente odontológico é de grande importância, pois, estão expostos a várias contaminações, infecções, etc. Nesse contexto, garantir a proteção do usuário, a proteção da vida, saúde e segurança contra os riscos por práticas no fornecimento de produtos e serviços. Orientar a equipe sobre o controle de infecção na prática odontológica é de responsabilidade do cirurgião dentista.

Knackfuss (2011) assevera a importância da conscientização sobre a prevenção e a implementação de métodos como o uso de luvas, de máscaras, óculos de proteção e imunização contra o vírus da hepatite B (HBV) por meio de vacina. Entretanto, muitos não utilizam uma série de procedimentos de controle de infecção.

Martoni (2010) relata que o sangue e a saliva potencializam a possibilidade de concentração de vírus e bactérias patogênicas, fator agravado quando não há um controle adequado da infecção cruzada, colocando em risco a saúde de pacientes e demais pessoas da equipe odontológicas. Nesse contexto os Equipamentos de Proteção Individual (E.P.I) e barreiras protetoras para isolar o contato direto com equipamentos que devem ser previamente desinfetados, são importantes no controle de infecções.

Alguns órgãos de saúde, como, Center for Disease Control (CDC), American Dental Association (ADA), Ministério da Saúde, elaboraram diretrizes 
a serem seguidas pelo profissional e sua equipe. Estas diretrizes têm como objetivo central combater as infecções no ambiente odontológico, e são constantemente aprimoradas com o intuito de tornar o atendimento odontológico cada vez mais seguro

\section{MATERIAL E MÉTODOS}

Este estudo trata-se de uma revisão de literatura de caráter exploratório. Para Moresi (2003), a revisão de literatura é uma das etapas fundamentais para o estudo, pois fornece a fundamentação teórica sobre o tema e a construção do conceito que dará suporte ao desenvolvimento da pesquisa. Somado a isso, o autor acrescenta que a revisão de literatura é o resultado dos levantamentos e análises já publicados sobre o tema da pesquisa, tendo como objetivo a contextualização teórica do trabalho dentro da área de estudo.

Segundo Gil (2010), as pesquisas exploratórias têm como objetivo proporcionar maior familiaridade com o problema, com vistas a torná-lo mais explícito ou a construir hipóteses. Completando o que afirma Gil tem-se Netto (2006, apud SOUZA 2008) ao afirmar que a pesquisa exploratória “estabelece critérios, métodos e técnicas para elaboração de uma pesquisa e visa oferecer
Desta forma o presente trabalho tem como principal objetivo relatar através de pesquisas bibliográficas sobre a importância do controle da infecção cruzadas na odontologia, seus riscos e diretrizes.

informações sobre o objeto desta e orientar a formulação de hipóteses".

O levantamento bibliográfico foi desenvolvido a partir de materiais já analisados e publicados por meios escritos e eletrônicos, como livros, artigos científicos e páginas de websites, segundo modelo de Gil (2007).

Para esta revisão foram utilizados como meios de consultas, artigos científicos da base de dados virtuais: PubMed (Public Medline), MEDLINE (Sistema Online de Busca e Análise de Literatura Médica), SciElo (Scientific Eletronic Library Online), LILACS (Literatura LatinoAmericana e do Caribe em Ciências da Saúde), via portal BVS (Biblioteca Virtual em Saúde), bem como revistas científicas e consultas complementares ao acervo da biblioteca central do Centro Universitário Tiradentes (UNIT- AL). As palavraschaves utilizadas junto ao DeCS para a busca de artigos e periódicos foram: Infecção cruzada; Odontologia; Educação em saúde. 


\section{RESULTADOS}

No intuito de reunir todas as informações e avanços no processo de infecção cruzada na odontologia com evidências que facilitem a triagem e o direcionamento dos procedimentos adotados no atendimento ao usuário do tratamento odontológico, adotou-se como critério de inclusão artigos na língua portuguesa publicada entre 2010 e 2019, na qual estivessem presentes maiores informações sobre a complexidade da humanização em termo atual na área da Saúde Coletiva e nos serviços públicos de saúde no ambiente odontológico, excluindo-se artigos incompletos com títulos que não estavam diretamente relacionados ao tema da pesquisa e/ou que não continham dados relevantes relacionados ao objeto de estudo.

No LILACS, a busca resultou em 14 publicações, sendo 12 artigos não contribuíam com os objetivos do estudo. No SciElo, a busca resultou em 65 referências, sendo que 62 não contribuía para pesquisa. No banco de dados MEDLINE, a busca resultou em 370 publicações sendo que 367 estavam em línguas estrangeiras sem publicações traduzidas. No PubMed, foram encontrados 125 artigos sendo que 130 estavam em língua estrangeira sem publicações traduzidas.

Quadro 1. O resultado da busca pelos artigos está representado na tabela abaixo.

\begin{tabular}{|l|c|c|c|}
\hline \multicolumn{1}{|c|}{ BASE DE DADOS } & $\begin{array}{c}\text { TOTAL DE } \\
\text { REFERENCIAS }\end{array}$ & $\begin{array}{c}\text { ARTIGOS } \\
\text { EXCLUIDOS }\end{array}$ & $\begin{array}{c}\text { ARTIGS } \\
\text { SELECIONADOS }\end{array}$ \\
\hline LILACS & 14 & 12 & 3 \\
\hline SCIELO & 65 & 62 & 3 \\
\hline MEDLINE & 370 & 367 & 4 \\
\hline PUBMED & 129 & 126 & 4 \\
\hline TOTAL & 578 & 564 & 14 \\
\hline
\end{tabular}

Fonte: autoria própria. 
A leitura exploratória verifica em que medida a obra consultada interessa à pesquisa. Esta pode ser feita mediante leitura de resumo, folha de rosto, índice, bibliografia e notas de rodapé (GIL, 2007). $\mathrm{Na}$ primeira fase, a busca pelos artigos se deu com a identificação do tema a partir da leitura exploratória do título e resumo de cada artigo. Nesta fase foram excluídas 512 referências, porque não incluíam no título ou resumo as palavras que contemplavam este estudo. A leitura seletiva é de natureza crítica e determina, de fato, qual material interessa à pesquisa. Para selecioná-lo, o autor deve ter em mente os objetivos (GIL, 2007). Para a leitura seletiva foi necessária a leitura dos artigos na íntegra para relacioná-los com o objetivo da pesquisa. A leitura seletiva não foi considerada definitiva, sendo complementada pela leitura analítica. Nesta fase, foram excluídas 46 referências, porque mesmo atendendo aos critérios da leitura exploratória, não atendiam ao objetivo do estudo, ou seja, não abordavam a relevância da humanização nos procedimentos odontológicos.

A análise dos dados foi contemplada pelas leituras exploratória, seletiva, analítica e interpretativa propostas por (GIL, 2007). A leitura analítica é de natureza objetiva e analisa os textos selecionados como definitivos com a finalidade de ordenar e sumariar as informações contidas nas fontes (GIL, 2007).

Por fim, a leitura interpretativa do material selecionado, buscou relacionar o conteúdo dos textos analisados com a temática da pesquisa. Sendo assim, os artigos foram analisados, contextualizados e os resultados foram elaborados baseandose em títulos e subtítulos, estabelecidos da seguinte forma: Historicidade, Discussão e Conclusão das (IDPs); revelando à importância de um atendimento humanizado, levando a conhecimento da população e de todas as áreas de saúde, os benefícios trazidos pelo modo de ser essencial.

Depois da primeira leitura, os artigos foram relidos com o objetivo de realizar uma análise interpretativa da questão norteadora estabelecida. Após a leitura, foi construído o quadro sinóptico das informações encontradas no material. 
Quadro 1. Detalhamento das etapas da revisão sistemática integrativa.

\begin{tabular}{|c|c|c|c|}
\hline $\begin{array}{l}\text { TÓPICOS DE } \\
\text { CADA ETAPA }\end{array}$ & \multicolumn{3}{|c|}{ DETALHAMENTO DE CADA TÓPICO } \\
\hline TEMA & \multicolumn{3}{|c|}{ Infecção cruzada na odontologia: riscos e diretrizes. } \\
\hline $\begin{array}{c}\text { PERGUNTA } \\
\text { NORTEADORA }\end{array}$ & \multicolumn{3}{|c|}{ Quais os riscos e diretrizes da Infecção cruzada no tratamento odontologia? } \\
\hline $\begin{array}{l}\text { OBJETIVO } \\
\text { GERAL }\end{array}$ & \multicolumn{3}{|c|}{$\begin{array}{l}\text { Discutir através de levantamentos bibliográficos a infecção cruzada, seus } \\
\text { riscos e diretrizes. }\end{array}$} \\
\hline Estratégias de busca & \multicolumn{3}{|c|}{$\begin{array}{l}\text { 1. Cruzamento de descritores por meio do operador booleano AND, } \\
\text { NOT, OR; } \\
\text { 2. Uso de aspas nos politermos (descritor com mais de um termo) para } \\
\text { que a varredura de artigos científicos contemplasse o termo exato; } \\
\text { 3. Uso de descritores estruturados (codificação) no DECS ou MESH; } \\
\text { 4. Uso de metadados (filtros) nas bibliotecas virtuais; } \\
\text { 5. Uso de descritores em inglês para ampliar o número de artigos. }\end{array}$} \\
\hline \multirow{3}{*}{$\begin{array}{l}\text { Bancos de } \\
\text { terminologias }\end{array}$} & Banco & & Link \\
\hline & c & & /decs.bvs.br/ \\
\hline & $\mathrm{h}$ & https://v & cbi.nlm.nih.gov/mesh \\
\hline \multirow{2}{*}{$\begin{array}{l}\text { Descritores livres e } \\
\text { estruturados }\end{array}$} & Descritor & DeCS (Registro) & MeSH (Identificador Único) \\
\hline & $\begin{array}{l}\text { Controle de } \\
\text { infecção }\end{array}$ & 30037 & D017053 \\
\hline
\end{tabular}




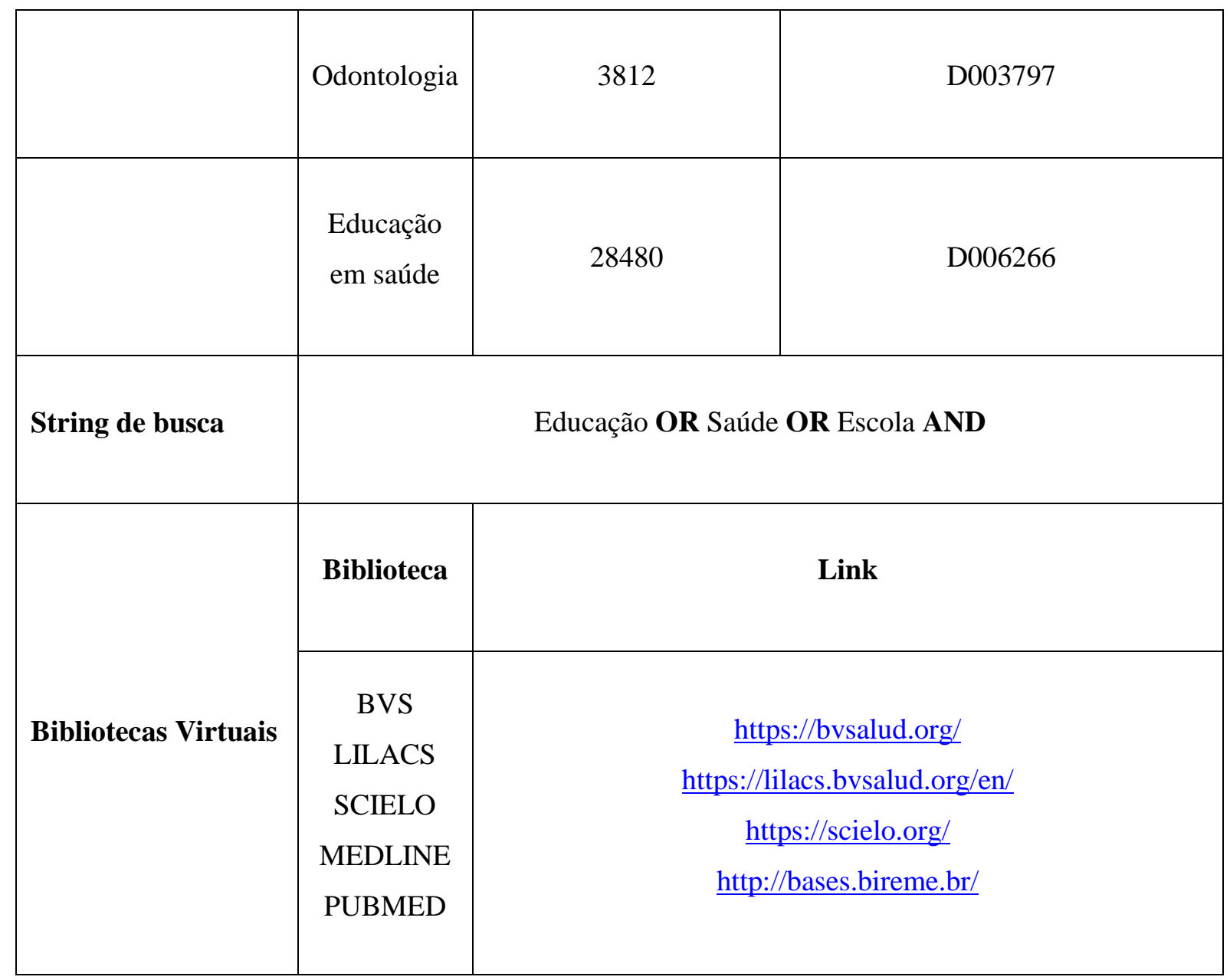

Fonte: autoria própria.

Quadro 2. Quadro síntese.

\begin{tabular}{|c|c|c|c|}
\hline TítULO DO ARTIGO & $\begin{array}{c}\text { ANO DE } \\
\text { PUBLICAÇÃo }\end{array}$ & AUTOR & $\begin{array}{c}\text { MÉTODO } \\
\text { APLICADO }\end{array}$ \\
\hline $\begin{array}{c}\text { O Cuidado á puérpera com } \\
\text { HIV/AIDS no Alojamento } \\
\text { Conjunto: A Visão da Equipe } \\
\text { de Enfermagem. }\end{array}$ & 2012 & ARAÚJO, C.L.F., & $\begin{array}{c}\text { Estudo de natureza } \\
\text { descritiva e } \\
\text { exploratória com } \\
\text { abordagem qualitativa. }\end{array}$ \\
\hline $\begin{array}{c}\text { Microbiological Analysis of } \\
\text { Orthodontic Pliers. }\end{array}$ & 2011 & AZEREDO, F. et al & $\begin{array}{c}\text { Estudo quantitativo, } \\
\text { descritivo e } \\
\text { transversal. }\end{array}$ \\
\hline $\begin{array}{c}\text { Contaminação do ambiente } \\
\text { odontológico por aerossóis }\end{array}$ & 2011 & BARRETO, A. C. & $\begin{array}{c}\text { Estudo quantitativo, } \\
\text { descritivo e } \\
\text { transversal. }\end{array}$ \\
\hline
\end{tabular}




\begin{tabular}{|c|c|c|c|}
\hline $\begin{array}{l}\text { durante atendimento clínico } \\
\text { com uso de ultrassom. }\end{array}$ & & & \\
\hline $\begin{array}{l}\text { Conduta do cirurgião-dentista } \\
\text { frente a acidentes biológicos. }\end{array}$ & 2012 & $\begin{array}{l}\text { BRAGANÇA DPP, } \\
\text { FERNANDES MM, } \\
\text { SASSI C, } \\
\text { FRANCESQUINI L }\end{array}$ & $\begin{array}{l}\text { Estudo descritivo e } \\
\text { exploratório. }\end{array}$ \\
\hline $\begin{array}{l}\text { A visão da ciência em relação à } \\
\text { Aids: As ciências da Aids e a } \\
\text { HIV e as ciências. }\end{array}$ & 2015 & CAMARGO, K.R & $\begin{array}{c}\text { Estudo de caso } \\
\text { múltiplo transversal e } \\
\text { de cunho exploratório. }\end{array}$ \\
\hline $\begin{array}{l}\text { Avaliação dos procedimentos } \\
\text { realizados por cirurgiões- } \\
\text { dentistas da região de cascavel- } \\
\text { PR visando ao controle de } \\
\text { biossegurança }\end{array}$ & 2012 & $\begin{array}{l}\text { ENGELMANN AI, } \\
\text { DAÍ AA, MIURA } \\
\text { CSN, BREMM LL, } \\
\text { FAGLIONI DC et } \\
\text { al. }\end{array}$ & $\begin{array}{c}\text { Estudo de natureza } \\
\text { descritiva e } \\
\text { exploratória com } \\
\text { abordagem qualitativa. }\end{array}$ \\
\hline $\begin{array}{l}\text { Vacinação contra hepatite B e } \\
\text { fatores associados entre } \\
\text { cirurgiões-dentistas }\end{array}$ & 2012 & $\begin{array}{l}\text { FERREIRA RC, } \\
\text { GUIMARÃES } \\
\text { ALS, PEREIRA } \\
\text { RD, ANDRADE } \\
\text { RM, XAVIER RP } \\
\text { et al. }\end{array}$ & $\begin{array}{c}\text { Estudo de natureza } \\
\text { descritiva e } \\
\text { exploratória com } \\
\text { abordagem qualitativa. }\end{array}$ \\
\hline $\begin{array}{l}\text { Biossegurança na área de } \\
\text { saúde: Uma abordagem } \\
\text { interdisciplinar. }\end{array}$ & 2012 & $\begin{array}{l}\text { FIALHO ACV, } \\
\text { MOREIRA FMA, } \\
\text { ALMEIDA CL, } \\
\text { FERREIRA AAP, } \\
\text { SOUSA CP }\end{array}$ & $\begin{array}{c}\text { Estudo de caso } \\
\text { múltiplo transversal e } \\
\text { de cunho exploratório. }\end{array}$ \\
\hline Cross Infection Control. & 2012 & $\begin{array}{c}\text { KHAN, A. A. ET } \\
\text { AL }\end{array}$ & $\begin{array}{l}\text { Estudo quantitativo, } \\
\text { descritivo e } \\
\text { transversal. }\end{array}$ \\
\hline $\begin{array}{l}\text { Dor odontológica e indicadores } \\
\text { de risco em jovens. }\end{array}$ & 2011 & $\begin{array}{l}\text { KNACKFUSS AP, } \\
\text { COSTENARO } \\
\text { RGS, ZANATTA } \\
\text { FB. }\end{array}$ & $\begin{array}{c}\text { Estudo descritivo e } \\
\text { exploratório. }\end{array}$ \\
\hline
\end{tabular}




\begin{tabular}{|c|c|c|c|}
\hline $\begin{array}{l}\text { Avaliação da contaminação } \\
\text { microbiana dos procedimentos } \\
\text { de radiologia no ambiente } \\
\text { odontológico }\end{array}$ & 2010 & $\begin{array}{l}\text { MARTONI, S.C.; } \\
\text { PINHEIRO, S.L. }\end{array}$ & $\begin{array}{c}\text { Estudo de caso } \\
\text { múltiplo transversal e } \\
\text { de cunho exploratório }\end{array}$ \\
\hline $\begin{array}{l}\text { Testes rápidos para diagnóstico } \\
\text { de HIV: uma revisão narrativa } \\
\text { da literatura. }\end{array}$ & 2015 & MORESCHI & $\begin{array}{c}\text { Estudo descritivo e } \\
\text { exploratório }\end{array}$ \\
\hline Biossegurança: uma revisão & 2010 & $\begin{array}{l}\text { PENNA PMM } \\
\text { et. al. }\end{array}$ & $\begin{array}{c}\text { Estudo quantitativo, } \\
\text { descritivo e transversa } \\
1\end{array}$ \\
\hline $\begin{array}{l}\text { HIV/AIDS Knowledge and its } \\
\text { Implications on Dentists. }\end{array}$ & 2014 & PRABHU, A. et al & $\begin{array}{c}\text { Estudo descritivo e } \\
\text { exploratório. }\end{array}$ \\
\hline $\begin{array}{l}\text { Photodynamic inactivation of } \\
\text { Candida ssp. on denture } \\
\text { stomatitis. A clinical trial } \\
\text { involving palatal mucosa and } \\
\text { prosthesis disinfection. }\end{array}$ & 2018 & SENNA, A.M. et al & $\begin{array}{c}\text { Estudo quantitativo, } \\
\text { descritivo e transversal }\end{array}$ \\
\hline $\begin{array}{l}\text { Hepatite B e HIV/AIDS - A } \\
\text { representação social das } \\
\text { doenças e a análise da } \\
\text { imunização contra o vírus da } \\
\text { hepatite B entre os alunos de } \\
\text { Odontologia. }\end{array}$ & 2016 & WAKAYAMA & $\begin{array}{c}\text { Estudo de natureza } \\
\text { descritiva e } \\
\text { exploratória com } \\
\text { abordagem qualitativa }\end{array}$ \\
\hline $\begin{array}{l}\text { Perfil de acadêmicos de } \\
\text { odontologia sobre } \\
\text { biossegurança. }\end{array}$ & 2012 & XEREZ JE ET. al. & $\begin{array}{c}\text { Estudo descritivo e } \\
\text { exploratório. }\end{array}$ \\
\hline
\end{tabular}

Fonte: autoria própria.

\section{DISCUSÃO}

Segundo Martoni (2010), durante todas essas fases do processamento odontológicos podem acontecer Infecções cruzadas. O controle da contaminação em odontologia com a utilização de desinfetantes, barreiras de proteção e sobre luvas, são mecanismos utilizados na prevenção. Nesse contexto a utilização 
simultânea desses três métodos de proteção para alcançar níveis aceitáveis de contaminação.

O programa do ministério da saúde voltado para evitar a transmissão dessas epidemias, tratando a biossegurança como principal objetivo na preservação do profissional e do paciente, instruindo atuantes da área da saúde a um domínio de técnicas para diminuir ou até mesmo excluir os perigos de infecção dentro do ambiente odontológico. (PENNNA,2010)

$\mathrm{O}$ despreparo dos profissionais em odontologia são o maior causador de acidentes ocupacionais, a falta de habilidade em lidar com possíveis situações de perigo pode deixar em risco a saúde do paciente e o próprio profissional. Vale salientar que, em muitos casos os pacientes não estão cientes do seu estado de saúde e se são ou não portadores de alguma doença infectocontagiosa, a exposição de exsudato, saliva e sangue que podem estar contaminados pelo vírus da Hepatite B ou pelo vírus da Imunodeficiência Humana, dentre outras doenças, eleva a necessidade do conhecimento e o correto manejo das técnicas de biossegurança, que são de suma importância. (XEREZ,2012)

Ainda há muito preconceito em relação ao atendimento de pacientes acometidos ao Vírus da Imunodeficiência Humana (HIV), provavelmente impulsionado pela falta de informação perante a doença e seus meios de transmissão. (SENA ET. al. 2018)

Em seu entendimento Wakayama (2016), relata o conhecimento referente ao HIV e ao VHB pelos profissionais da área da odontologia e pelos acadêmicos, como fundamental, através do entendimento da patologia pode-se combater a discriminação sofrida por pacientes que sofrem com essa doença. É necessário que os futuros profissionais de odontologia saibam lidar com situações de atendimento a portadores de HIV, para que o paciente tenha um tratamento adequado no atendimento odontológico. Desse modo, a utilização de técnicas de biossegurança é de grande importância entendendo que todo paciente deve ser considerado infectado por algum tipo de vírus, e que as normas de atendimento devem ser iguais para todos os indivíduos.

Os testes rápidos podem ser um grande recurso para os profissionais da área da saúde contribuindo para um diagnóstico rápido, colabora na assistência ao paciente, principalmente em ocasiões que ocorrem acidentes com materiais perfuro-cortantes. (MORESCHI,2015). 


\section{CONCLUSÃO}

Transmissão viral no consultório odontológico é uma realidade, o risco existe e conceitos de controle de infecção em Ortodontia devem ser aplicados na pratica. É de suma importância que o dentista e sua equipe tenham conhecimento sobre os riscos como também a conscientização de seguir protocolo de segurança para $o$ controle de infecção.

O profissional em odontologia deve entender as vantagens que a realização do controle pode proporcionar a equipe de trabalho e ao paciente, transformando um

\section{REFERENCIAS}

ARAÚJO, C.L.F., et.al, O Cuidado á puérpera com HIV/AIDS no Alojamento Conjunto: A Visão da Equipe de Enfermagem. Esc. Anna Nery. v. 16, n. 1, p. 49-56, 2012.

AZEREDO, F. et al. Microbiological Analysis of Orthodontic Pliers. Dental Press Journal of Orthodontics, v. 16, n. 3, p. 103-112, 2011.

BRASIL. Ministério da Saúde. Hepatite B. Disponível em:

$<$ http://www.aids.gov.br/ptbr/publicogeral/o-que-sao-hepatites/hepatite-b $>$.

Acesso em: 23 março, 2019.

Ministério da Saúde. Secretaria de vigilância de saúde. Departamento de DST, Aids e Hepatites Virais. Protocolo Clínico e Diretrizes Terapêuticas para Prevenção da Transmissão Vertical de HIV, Sífilis e Hepatites Virais. Brasília: Ministério da Saúde, 2015. ambiente seguro para o profissional de saúde quanto ao tratamento a ser realizado.

Desta forma, identificando que a informação, conhecimento e aplicação dos recursos disponíveis em relação a prevenção é necessário. A prevenção é a forma mais eficaz para o combate destas patologias, diagnóstico precoce, desta forma realizar programas educativos, desenvolver o pensamento e a consciência crítica, sempre buscando a prevenção, deve ser a forma a ser adotada, voltada prioritariamente, nas questões do desenvolvimento humano.

\section{. Ministério da Saúde. Agência \\ Nacional de Vigilância Sanitária. Serviços Odontológicos: Prevenção e Controle de Riscos / Ministério da Saúde, Agência Nacional de Vigilância Sanitária. - Brasília: Ministério da Saúde, 2006.}

BARRETO, A. C. B. et al. Contaminação do ambiente odontológico por aerossóis durante atendimento clínico com uso de ultrassom. Periodontia, v.21, n.2, p.79-84, 2011.

BRAGANÇA DPP, FERNANDES MM, SASSI C, FRANCESQUINI L. Conduta do cirurgião-dentista frente a acidentes biológicos. Odonto Jan 2012

CAMARGO, K.R. A visão da ciência em relação à Aids: As ciências da Aids e a HIV e as ciências. Rio de Janeiro: Relume Dumará; 2015.

ENGELMANN AI, DAÍ AA, MIURA CSN, BREMM LL, FAGLIONI DC et al. Avaliação dos procedimentos realizados por cirurgiões-dentistas da região de 
cascavel-PR visando ao controle de biossegurança. Odonto, Abr 2012 Abr

FERREIRA RC, GUIMARÃES ALS, PEREIRA RD, ANDRADE RM, XAVIER

$\mathrm{RP}$ et al. Vacinação contra hepatite $\mathrm{B}$ e fatores associados entre cirurgiõesdentistas. Brasileira de epidemiológica. 2012.

FIALHO ACV, MOREIRA FMA, ALMEIDA CL, FERREIRA AAP, SOUSA CP. Biossegurança na área de saúde: Uma abordagem interdisciplinar. Edufscar. 2011

GIL, A. C. Métodos e técnicas de pesquisa social. 5.ed. São Paulo: Atlas, 1999.

Como elaborar projetos de pesquisa. 5. ed. São Paulo: Atlas, 2010. Métodos e técnicas de pesquisa social. 5. ed. São Paulo: Atlas, 2007.

KHAN, A. A. et al. Cross Infection Control. Pakistan Oral \& Dental Journal, v.32, n.1, p 31, 2012.

KNACKFUSS AP, COSTENARO RGS, ZANATTA FB. Dor odontológica e indicadores de risco em jovens. Rev. Gaúcha Odontologia 2011.

MARTONI, S.C.; PINHEIRO, S.L. Avaliação da contaminação microbiana dos procedimentos de radiologia no ambiente odontológico. In: Anais do XV encontro de Iniciação Científica da PUCCampinas, 2010.
MORESCHI, L. B. et al. Testes rápidos para diagnóstico de HIV: uma revisão narrativa da literatura. Revista da graduação, v. 8, n. 1, 2015

PENNA PMM, AQUINO CF, CASTANHEIRA DD, BRANDI IV, CANGUSSU ASR, MACEDO

SOBRINHO E, et al. Biossegurança: uma revisão. Arq Inst Biol. 2010.

PRABHU, A. et al. HIV/AIDS Knowledge and its Implications on Dentists. Journal of Natural Science, Biology and Medicine, v.5, n.2, p.303-307, 2014.

SENNA, A.M. et al. Photodynamic inactivation of Candida ssp. on denture stomatitis. A clinical trial involving palatal mucosa and prosthesis disinfection. Photodiagnosis and Photodynamic Therapy. v. 22, p. 212-216, 2018.

WAKAYAMA, Bruno. Hepatite B e HIV/AIDS - A representação social das doenças e a análise da imunização contra $o$ vírus da hepatite B entre os alunos de Odontologia. Dissertação de Mestrado apresentada à Faculdade de Odontologia de Araçatuba da Universidade Estadual Paulista, Araçatuba, 2016

XEREZ JE, GALVÃO HC, MAIA CADM, GORDÓN-NÚÑEZ MA, SILVA JÚNIOR FL DA, COSTA NETO H. Perfil de acadêmicos de odontologia sobre biossegurança. Rev. Fac Odontol Porto Alegre. 2012. 